\title{
Video-Assisted Thyroidectomy for Selected Cases of Differentiated Thyroid Carcinoma. Initial Experience in Colombia
}

\author{
Andrés Chala1 ${ }^{*}$, Alvaro Sanabria², Adonis Ramírez ${ }^{3}$ \\ ${ }^{1}$ General Surgery Section, Department of Head and Neck Surgery, Universidad de Caldas, Manizales, Colombia \\ ${ }^{2}$ Oncology Unit, Hospital Pablo Tobón Uribe, Department of Head and Neck Surgery, Universidad de Antioquia, \\ Medellín, Colombia \\ ${ }^{3}$ General Surgery Section, Department of Head and Neck Surgery, Universidad Surcolombiana, Neiva, Colombia \\ Email: andreschalag@hotmail.com
}

Received 8 September 2014; revised 23 October 2014; accepted 24 November 2014

Copyright (C) 2014 by authors and OALib.

This work is licensed under the Creative Commons Attribution International License (CC BY). http://creativecommons.org/licenses/by/4.0/

c) (i) Open Access

\section{Abstract}

Background: Minimally invasive video-assisted thyroidectomy (MIVAT) has been proposed as an alternative procedure to get the same completeness as a conventional thyroidectomy in selected cases of differentiated thyroid cancer. It's considered as safe as the conventional procedure. $\mathrm{Ob}$ jective: The purpose of the study was to do a retrospective evaluation in a series of patients who underwent MIVAT for thyroid nodule or thyroid cancer over a two and a half year period, in two academic centers in Colombia in terms of the completeness of the surgical resection, morbidity and short-term recurrence. Results: 45 patients underwent a MIVAT, and 20 had also a central neck dissection (CND); frozen section study was realized in 9 cases. The final pathology showed 27 patients with papillary carcinomas, and 1 patient with incidental medullary carcinoma. Postoperative complications included temporary recurrent nerve paralysis $(1.1 \%)$, permanent recurrent nerve paralysis $(1.1 \%)$, temporary hypocalcaemia $(4.4 \%)$ and postoperative seroma $(8.8 \%)$ No definitive hypoparathyroidism was found. The short term follow-up didn't show recurrences. Conclusion: With this initial experience, we consider that this technique could be proposed as an alternative procedure to conventional surgery, including the resection of selected small thyroid carcinomas as other authors have proposed.

\section{Keywords}

Video-Assisted Thyroidectomy, Thyroid Cancer

Subject Areas: Oncology, Otorhinolaryngology, Surgery \& Surgical Specialties

\footnotetext{
${ }^{*}$ Corresponding author.
}

How to cite this paper: Chala, A., Sanabria, A. and Ramírez, A. (2014) Video-Assisted Thyroidectomy for Selected Cases of Differentiated Thyroid Carcinoma. Initial Experience in Colombia. Open Access Library Journal, 1: e1158. 


\section{Introduction}

The main goal in the treatment of a malignancy is to cure without morbidity and with a good cost-effective ratio. Currently, thyroid tumors have been treated by open thyroidectomy since its first description more than a century ago. Minimally invasive thyroidectomy (MIVAT) was conceived in Europe by Miccoli and co-workers in 1999 for small nodules as an alternative to open thyroidectomy with expected advantages of less tissue trauma and more esthetic results [1]. More than a decade has passed since its description and the experience with the technique have grown all over the world, which contributed to its wide use, not only for benign nodules but also for thyroid cancer. Actually, MIVAT can be used in patients without previous surgery or neck radiotherapy and without chronic thyroiditis and with nodules lower than 30 - $35 \mathrm{~mm}$, a cranio-caudal axis lower than $7 \mathrm{~cm}$ and a volume lower than $35 \mathrm{ml}$. Previous studies show that it can be successfully made in almost $8 \%-12 \%$ of thyroidectomies with a conversion rate lower than $3 \%-5 \%$ [2]. Once the learning curve is achieved, the procedure exhibits similar post-operative complications to the open technique like transient vocal cord paralysis (3.2\%), definitive recurrent laryngeal nerve paralysis $(0.04 \%-1 \%)$, temporary hypocalcemia $(6 \%-8.1 \%)$, definitive hypoparathyroidism (0.8\%) and hematoma (0.3\%) [3] [4]. This new surgical approach has reached many adepts who agree that the main benefit is a better cosmetic result [5]. Some studies comparing post-operative pain and length of hospital stay favor the MIVAT approach [5] [6]. Another advantage is the reduction of post-thyroidectomy voice and swallowing symptoms probably due to less injury to the fine anastomotic branches connecting the inferior recurrent laryngeal nerve and the external branch of the superior laryngeal nerve or their anastomosis with the sympathetic cervical chain [7]. The main disadvantage is related to the learning curve necessary to do a safe procedure. It usually takes longer operative time at the beginning and needs specific training in comparison with the conventional one [8] [9]. It is recommended to do at least 30 procedures to get the curve. There is no consensus about its cost-effectiveness, but it seems to be better than open access for hemi-thyroidectomy [10]. Besides, there is no consensus about the advantages of using simultaneous intraoperative monitoring of the recurrent laryngeal nerve in MIVAT because it adds additional time to dissect the vagus nerve and because traction and thermal RLN injuries cannot be avoided with neuromonitoring. The careful dissection and identification of the external branch of the superior laryngeal nerve and also the inferior laryngeal nerve during the procedure are the best way to avoid injuries. The monitoring is a meaningful adjunct to the visual identification of nerves and enables surgeons to feel more comfortable with MIVAT but does not replace a judicious surgical procedure [11]-[13].

Almost 20\% of the MIVAT surgery is done for cancer [3] [4] [14]. Due to the overwhelmed new cases of early thyroid carcinoma, most of them incidental and lower than $2 \mathrm{~cm}$, the MIVAT gives the chance to do a safe and cosmetic surgery without differences in terms of morbidity, mortality and recurrence. Compared with conventional thyroidectomy, different trials have not shown differences in outcome, $\mathrm{I}^{131}$ uptake or thyroglobulin levels for MIVAT, so it is a valid option to treat low- and intermediate-risk PTC patients [3] [15] [16]. Whenever necessary, a central neck dissection is feasible and safe and has similar results as conventional thyroidectomy [17]-[20].

In this study we retrospectively evaluate the results obtained in a series of patients who underwent MIVAT for thyroid nodule or thyroid cancer over a two and a half year period, in two academic centers in Colombia in terms of the completeness of the surgical resection, morbidity and short-term recurrence.

\section{Materials and Methods}

Between November 2011 and June 2013, 45 patients underwent MIVAT at the Head and Neck service of the Universidad de Caldas in Manizales Colombia and the Universidad Surcolombiana in Neiva, Colombia. Eligibility criteria for MIVAT were thyroid nodules less than $30 \mathrm{~mm}$ on the largest diameter, an estimated thyroid volume within the normal range (less than $30 \mathrm{~mL}$ ), without chronic thyroiditis and no previous neck surgery or radiation therapy. All the patients had complete evaluation (medical history, indirect laryngoscopy, thyroid ultrasound, fine needle biopsy aspiration and report according to Bethesda system). The medical records of these patients were retrospectively reviewed.

The operative technique included a MIVAT access completing a thyroid lobectomy, total thyroidectomy and a central neck dissection when necessary. No drains were used in any patient. Serum calcium and phosphorus levels were measured in the postoperative time. When a total thyroidectomy was done, patients received oral calcium during two weeks, only in presence of clinical suggestion of postoperative hypocalcemia. (Serum calcium level below $8.0 \mathrm{mg} / \mathrm{dL}$ ). The patients with a total thyroidectomy initially received $1-1.5 \mathrm{mcg} / \mathrm{Kg}$ of levothy- 
roxine, but the final dose was related with the needs to suppress or not according to the definitive pathology report. The post-operative clinical finding of seroma was recorded even if it required drainage by puncture or not. An indirect laryngoscopy was done in all patients. When necessary a fiber optic laryngoscopy was done to confirm or exclude alterations in vocal cord mobility. ${ }^{131}$ I ablation (RAI) was performed in patients with differentiated thyroid cancer according to risk factors [21] and a post-therapy whole body scan at the eight day was accomplished. Low risk patients didn't receive radioiodine therapy. Serum thyroglobulin (sTg) and anti-Tg antibody levels under LT4 treatment was assessed every 3 to 6 months after surgery, and a chest X-ray and a neck ultrasound (US) was made each year after surgery. The operation time, final histopathology results, complications and length of hospital stay was registered.

\section{Results}

Forty five patients underwent MIVAT during study time ( $8 \%$ of all thyroidectomies made during that period). There were 42 female (93\%). The medium age was $42 \pm 12$ years. Indications for surgery were follicular neoplasia (15), papillary carcinoma (25), goiter toxic (7) and hyperthyroidism caused by an autonomous nodule (1). The mean size of the nodules measured by ultrasound was $\leq 2 \mathrm{~cm}$ in 31 cases $(68 \%)$ and 2 to $3 \mathrm{~cm}$ in 14 patients (32\%). The average volume of the thyroid gland was 6 - $8 \mathrm{cc}$. Any patient had intraoperative findings suggesting local invasion. Total thyroidectomy was performed in 38 patients and lobectomy in 7 patients. Central neck dissection (CND) was also done in 20 cases (52\%) which lymph node involvement was suspicious clinically. Frozen section was done in 9 cases of follicular neoplasia ( 7 suggested no malignancy, so the procedure was only a lobectomy and 2 suggested carcinoma and a total thyroidectomy was performed). Mean operative time was $50 \pm$ 15 min for lobectomy, $62 \pm 11$ min for total thyroidectomy, $12 \pm 3$ min were added when a central neck dissection was necessary and additional $30 \pm 8$ minutes were added when a frozen section was done. We didn't have any tumor rupture during the procedure. A total of 8 patients were discharged the same day of the operation under a supervised ambulatory surgery program. The others (82\%) had a short-stay hospitalization (between 12 18 hours).

Final histology revealed follicular adenoma in 7 patients (15.5\%), Hashimoto thyroiditis in 2 patients (4.5\%), goiter in 5 patients (11\%), incidental papillary micro carcinoma (into the goiter) in 3 patients (6.7\%), papillary carcinoma in 24 patients (53.3\%) and medullary carcinoma as an incidental finding in one patient (2\%). The frozen section in all cases was able to diagnose correctly the histology of the nodule and a consequent intraoperative decision was made. The final pathology study confirmed the frozen section result in all cases.

The final stage for carcinoma cases was pT1 in 20 patients and pT2 in 4 patients. Five cases had multifocality (21\%). Lymph node metastases in central compartment were found in 14 cases (70\%) of the 20 patients in which CND was performed. The other six patients who underwent selective central node dissections had inflammatory lymph nodes. The mean number of nodes dissected and removed was $14 \pm 7$ (range 7 - 28). The patient with the medullary carcinoma had a $1.5 \mathrm{~cm}$ tumor size with negative margins and without positive lymph nodes.

Conversion to an open procedure was not required in any procedure. Post-operative complications included 1temporary recurrent nerve paralysis (1.1\% of the nerves at risk), 1 permanent recurrent nerve paralysis (1.1\% of the nerves at risk), two transient hypocalcaemia cases (4.4\%) and four postoperative seroma (8.8\%) (3 of them treated with a unique percutaneous drainage). The permanent recurrent nerve palsy was due to thermal injury since the nerve was recognized and dissected during operation. This patient needed a second procedure with an external thyroplasty with Teflon which successfully corrected the voice impairment and the glottal insufficiency, four months after the initial surgery.

A total of six patients with high risk cancer were considered candidates to receive ${ }^{131} \mathrm{I}$ ablation (RAI). The dose was from $30-50$ mci of ${ }^{131} \mathrm{I}$. A post-therapy whole body scan at the eight day was accomplished and showed small neck uptake without evidence of regional or distant metastasis. The mean follow-up period was 20 \pm 5 months (range: 12 - 31). The sTg was undetectable $(<0.2 \mathrm{ng} / \mathrm{mL})$ in 10 cases, and between $0.2-2.0$ in 18 cases. The US neck exam didn't show thyroid remnants or lymph node involvement in any case and the chest $\mathrm{X}$-ray was normal. The calcitonin level, the ultrasound neck and chest X-ray were normal in the case of medullary carcinoma.

\section{Discussion}

Open total or partial thyroidectomy has been the standard of care for thyroid cancer during a century. However, 
the appearance of minimally invasive techniques for head and neck conditions opened a new possibility of treatment for thyroid cancer. The first attempt was the minimally invasive video-assisted thyroidectomy designed by Miccoli et al. [22]. Soon, other surgical techniques as breast-access minimally invasive thyroidectomy [23], axillary robotic-assisted thyroidectomy [24] and face-lift robotic assisted thyroidectomy [25] has also been suggested as minimally invasive. Nonetheless, up to date only MIVAT has supported a global evaluation. The MIVAT technique is now used as an appropriate surgical approach to treat small nodules even if they are suspicious of carcinoma, because better esthetic results [26].

Some authors have raised a concern about its safety in terms of recurrence, related with the feasibility of a complete resection without oncologic contamination and seeding of the tumor in the thyroid bed [27]. However, many other authors have not found differences in comparison to open conventional approach [28]-[30], and have proposed that is a feasible and safe technique in differentiated thyroid cancer [14]-[17].

One important fact, usually discussed in literature is the training curve for new procedures, which achieve strong relevance in cancer cases. It is necessary to dominate the surgical technique in order to obtain good oncologic results. Authors have proposed a number of 10 to 60 MIVAT cases in order to get the training curve [31]-[33], but its achievement depends on previous experience of the surgeon and technical factors related with technology needs. As many studies have been made in specialized centers of developed countries, we decide to test all these factors in an initial cohort of MIVAT cases in a developing country.

Despite the short follow-up of our study, the safety results related with laryngeal nerve injury and definitive hypoparathyroidism were not different from those reported elsewhere [29] [30]. Our short experience is similar to our open conventional surgery results [34]. We don't routinely use recurrent laryngeal nerve neuromonitoring, and we reserve it only to reoperations. As these cases were carefully selected, we didn't considered its use. The only case with a recurrent laryngeal nerve injury was related with thermal damage and not with the inability to identify it during surgery. We didn't have any case of permanent hypoparathyroidism. We believe these results are due to the better visualization and magnification provided by the endoscope used to assist the dissection.

We didn't find biochemical, clinical or imaging evidence of persistent or recurrent thyroid cancer. Previously, Miccoli et al. [15] studied 221 patients with low and medium risk papillary carcinoma and didn't found differences in thyroglobulin levels or recurrence rates after 5 years of follow up. Del Rio et al. [35] and Di et al. [14] confirmed the same results in almost 100 patients. In our study, it was also possible to treat a small medullary carcinoma being detected as an incidental case. The completeness and feasibility of doing a complete central neck dissection when necessary was similar to reported by Bellantone et al. [19] and Neidich and Steward [17], with adequate numbers of malignant nodes resected.

Regarding the follow-up, the main limitation of this study is the short term of it, so a final conclusion related with the long term effectiveness of the surgical technique in oncological outcomes is still lacking. However, with this initial experience, we consider that this technique could be proposed as an alternative procedure to conventional surgery, including the resection of selected small thyroid carcinomas as others authors have proposed [17] [18] [20].

\section{Conclusion}

The MIVAT in selected cases of thyroid cancer is as safe as open conventional surgery, once the learning curve has been achieved. The technique is feasible in terms of the completeness of the resection and the possibility of doing a central neck dissection with the advantage of the magnifications of critical structures, with similar rates of morbidity and with the advantage of a better cosmetic result.

\section{References}

[1] Miccoli, P., Berti, P., Conte, M., Bendinelli, C. and Marcocci, C. (1999) Minimally Invasive Surgery for Thyroid Small Nodules: Preliminary Report. Journal of Endocrinological Investigation, 22, 849-851. http://dx.doi.org/10.1007/BF03343657

[2] Lombardi, C.P., Raffaelli, M., De Crea, C., D’Amore, A. and Bellantone, R. (2009) Video-Assisted Thyroidectomy: Lessons Learned after More than One Decade. Acta Otorhinolaryngologica Italica: Organo Ufficiale della Societa Italiana di Otorinolaringologia e Chirurgia Cervico-Facciale, 29, 317-320.

[3] Lombardi, C.P., Raffaelli, M., De Crea, C., D’Amore, A., Oragano, L., Salvatori, M. and Bellantone, R. (2010) VideoAssisted Thyroidectomy for Papillary Thyroid Carcinoma. Journal of Oncology, 2010, Article ID: 148542. http://dx.doi.org/10.1155/2010/148542 
[4] Terris, D.J., Angelos, P., Steward, D.L. and Simental, A.A. (2008) Minimally Invasive Video-Assisted Thyroidectomy: A Multi-Institutional North American Experience. Archives of Otolaryngology—Head \& Neck Surgery, 134, 81-84. http://dx.doi.org/10.1001/archoto.2007.22

[5] Chen, X.D., Peng, B., Gong, R.X., Wang, L., Liao, B. and Li, C.L. (2008) Endoscopic Thyroidectomy: An EvidenceBased Research on Feasibility, Safety and Clinical Effectiveness. Chinese Medical Journal, 121, 2088-2094.

[6] Liu, J., Song, T. and Xu, M. (2012) Minimally Invasive Video-Assisted versus Conventional Open Thyroidectomy: A Systematic Review of Available Data. Surgery Today, 42, 848-856. http://dx.doi.org/10.1007/s00595-012-0130-z

[7] Lombardi, C.P., Raffaelli, M., D’Alatri, L., De Crea, C., Marchese, M.R., Maccora, D., Paludetti, G. and Bellantone, R. (2008) Video-Assisted Thyroidectomy Significantly Reduces the Risk of Early Postthyroidectomy Voice and Swallowing Symptoms. World Journal of Surgery, 32, 693-700. http://dx.doi.org/10.1007/s00268-007-9443-2

[8] Dionigi, G., Boni, L., Rovera, F., Annoni, M., Villa, F. and Dionigi, R. (2008) Defining the Learning Curve for VideoAssisted Thyroidectomy. International Journal of Surgery, 6, S1-S3. http://dx.doi.org/10.1016/j.ijsu.2008.12.004

[9] Del Rio, P., Berti, M., Sommaruga, L., Arcuri, M.F., Cataldo, S. and Sianesi, M. (2008) Pain after Minimally Invasive Video Assisted and after Minimally Invasive Open Thyroidectomy-Results of a Prospective Outcome Study. Langenbeck's Archives of Surgery/Deutsche Gesellschaft fur Chirurgie, 393, 271-273. http://dx.doi.org/10.1007/s00423-007-0229-7

[10] Byrd, J.K., Nguyen, S.A., Ketcham, A., Hornig, J., Gillespie, M.B. and Lentsch, E. (2010) Minimally Invasive VideoAssisted Thyroidectomy versus Conventional Thyroidectomy: A Cost-Effective Analysis. Otolaryngology—Head and Neck Surgery: Official Journal of American Academy of Otolaryngology_Head and Neck Surgery, 143, 789-794. http://dx.doi.org/10.1016/j.otohns.2010.08.002

[11] Kandil, E., Wassef, S.N., Alabbas, H. and Freidlander, P.L. (2009) Minimally Invasive Video-Assisted Thyroidectomy and Parathyroidectomy with Intraoperative Recurrent Laryngeal Nerve Monitoring. International Journal of Otolaryngology, 2009, 1-4. http://dx.doi.org/10.1155/2009/739798

[12] Dionigi, G., Alesina, P.F., Barczynski, M., Boni, L., Chiang, F.Y., Kim, H.Y., Materazzi, G., Randolph, G.W., Terris, D.J. and Wu, C.W. (2012) Recurrent Laryngeal Nerve Injury in Video-Assisted Thyroidectomy: Lessons Learned from Neuromonitoring. Surgical Endoscopy, 26, 2601-2608. http://dx.doi.org/10.1007/s00464-012-2239-y

[13] Dedivitis, R.A. and Guimaraes, A.V. (2005) Identification of the External Branch of the Superior Laryngeal Nerve during Minimally Invasive Video-Assisted Thyroidectomy. Brazilian Journal of Otorhinolaryngology, 71, 326-328.

[14] Di, J.Z., Zhang, H.W., Han, X.D., Zhang, P., Zheng, Q. and Wang, Y. (2011) Minimally Invasive Video-Assisted Thyroidectomy for Accidental Papillary Thyroid Microcarcinoma: Comparison with Conventional Open Thyroidectomy with 5 Years Follow-Up. Chinese Medical Journal, 124, 3293-3296.

[15] Miccoli, P., Pinchera, A., Materazzi, G., Biagini, A., Berti, P., Faviana, P., Molinaro, E., Viola, D. and Elisei, R. (2009) Surgical Treatment of Low- and Intermediate-Risk Papillary Thyroid Cancer with Minimally Invasive Video-Assisted Thyroidectomy. The Journal of Clinical Endocrinology and Metabolism, 94, 1618-1622. http://dx.doi.org/10.1210/jc.2008-1418

[16] Lai, S.Y., Walvekar, R.R. and Ferris, R.L. (2008) Minimally Invasive Video-Assisted Thyroidectomy: Expanded Indications and Oncologic Completeness. Head \& Neck, 30, 1403-1407. http://dx.doi.org/10.1002/hed.20883

[17] Neidich, M.J. and Steward, D.L. (2012) Safety and Feasibility of Elective Minimally Invasive Video-Assisted Central Neck Dissection for Thyroid Carcinoma. Head \& Neck, 34, 354-358. http://dx.doi.org/10.1002/hed.21733

[18] Miccoli, P., Minuto, M.N., Berti, P. and Materazzi, G. (2009) Update on the Diagnosis and Treatment of Differentiated Thyroid Cancer. The Quarterly Journal of Nuclear Medicine and Molecular Imaging, 53, 465-472.

[19] Bellantone, R., Lombardi, C.P., Raffaelli, M., Boscherini, M., Alesina, P.F. and Princi, P. (2002) Central Neck Lymph Node Removal during Minimally Invasive Video-Assisted Thyroidectomy for Thyroid Carcinoma: A Feasible and Safe Procedure. Journal of Laparoendoscopic \& Advanced Surgical Techniques Part A, 12, 181-185. http://dx.doi.org/10.1089/10926420260188074

[20] Lombardi, C.P., Raffaelli, M., De Crea, C., Sessa, L., Rampulla, V. and Bellantone, R. (2012) Video-Assisted versus Conventional Total Thyroidectomy and Central Compartment Neck Dissection for Papillary Thyroid Carcinoma. World Journal of Surgery, 36, 1225-1230. http://dx.doi.org/10.1007/s00268-012-1439-X

[21] Cooper, D.S., Doherty, G.M., Haugen, B.R., Kloos, R.T., Lee, S.L., Mandel, S.J., et al. (2009) Revised American Thyroid Association Management Guidelines for Patients with Thyroid Nodules and Differentiated Thyroid Cancer. Thyroid: Official Journal of the American Thyroid Association, 19, 1167-1214. http://dx.doi.org/10.1089/thy.2009.0110

[22] Miccoli, P., Materazzi, G., Baggiani, A. and Miccoli, M. (2011) Mini-Invasive Video-Assisted Surgery of the Thyroid and Parathyroid Glands: A 2011 Update. Journal of Endocrinological Investigation, 34, 473-480.

[23] Ohgami, M., Ishii, S., Arisawa, Y., Ohmori, T., Noga, K., Furukawa, T. and Kitajima, M. (2000) Scarless Endoscopic 
Thyroidectomy: Breast Approach for Better Cosmesis. Surgical Laparoscopy, Endoscopy \& Percutaneous Techniques, 10, 1-4. http://dx.doi.org/10.1097/00129689-200002000-00001

[24] Lee, K.E., Rao, J. and Youn, Y.K. (2009) Endoscopic Thyroidectomy with the da Vinci Robot System Using the Bilateral Axillary Breast Approach (BABA) Technique: Our Initial Experience. Surgical Laparoscopy, Endoscopy \& Percutaneous Techniques, 19, e71-e75. http://dx.doi.org/10.1097/SLE.0b013e3181a4ccae

[25] Terris, D.J., Singer, M.C. and Seybt, M.W. (2011) Robotic Facelift Thyroidectomy: II. Clinical Feasibility and Safety. The Laryngoscope, 121, 1636-1641. http://dx.doi.org/10.1002/lary.21832

[26] Sahm, M., Schwarz, B., Schmidt, S., Pross, M. and Lippert, H. (2011) Long-Term Cosmetic Results after Minimally Invasive Video-Assisted Thyroidectomy. Surgical Endoscopy, 25, 3202-3208. http://dx.doi.org/10.1007/s00464-011-1693-2

[27] Benhidjeb, T., Witzel, K., Burghardt, J., Barlehner, E., Stark, M. and Mann, O. (2010) Endoscopic Minimally Invasive Thyroidectomy: Ethical and Patients Safety Considerations on the First Clinical Experience of an Innovative Approach. Surgical Endoscopy, Published Online. http://dx.doi.org/10.1007/s00464-010-1290-9

[28] Lombardi, C.P., Raffaelli, M., Princi, P., Lulli, P., Rossi, E.D., Fadda, G. and Bellantone, R. (2005) Safety of VideoAssisted Thyroidectomy versus Conventional Surgery. Head \& Neck, 27, 58-64. http://dx.doi.org/10.1002/hed.20118

[29] Pisanu, A., Podda, M., Reccia, I., Porceddu, G. and Uccheddu, A. (2013) Systematic Review with Meta-Analysis of Prospective Randomized Trials Comparing Minimally Invasive Video-Assisted Thyroidectomy (MIVAT) and Conventional Thyroidectomy (CT). Langenbeck's Archives of Surgery, 398, 1057-1068. http://dx.doi.org/10.1007/s00423-013-1125-y

[30] Radford, P.D., Ferguson, M.S., Magill, J.C., Karthikesalingham, A.P. and Alusi, G. (2011) Meta-Analysis of Minimally Invasive Video-Assisted Thyroidectomy. The Laryngoscope, 121, 1675-1681. http://dx.doi.org/10.1002/lary.21864

[31] Del Rio, P., Sommaruga, L., Cataldo, S., Robuschi, G., Arcuri, M.F. and Sianesi, M. (2008) Minimally Invasive Video-Assisted Thyroidectomy: The Learning Curve. European Surgical Research, 41, 33-36. http://dx.doi.org/10.1159/000127404

[32] Liu, S., Qiu, M., Jiang, D.Z., Zheng, X.M., Zhang, W., Shen, H.L. and Shan, C.X. (2009) The Learning Curve for Endoscopic Thyroidectomy: A Single Surgeon's Experience. Surgical Endoscopy, 23, 1802-1806. http://dx.doi.org/10.1007/s00464-009-0332-7

[33] Pons, Y., Verillaud, B., Blancal, J.P., Sauvaget, E., Cloutier, T., Le Clerc, N., Herman, P. and Kania, R. (2013) Minimally Invasive Video-Assisted Thyroidectomy: Learning Curve in Terms of Mean Operative Time and Conversion and Complication Rates. Head \& Neck, 35, 1078-1082. http://dx.doi.org/10.1002/hed.23081

[34] Chala, A. (2010) Estudio descriptivo de 12 años de cancer de tiroides en Manizales, Colombia. Revista Colombiana de Cirugía, 25, 13.

[35] Del Rio, P., Sommaruga, L., Pisani, P., Palladino, S., Arcuri, M.F., Franceschin, M. and Sianesi, M. (2009) Minimally Invasive Video-Assisted Thyroidectomy in Differentiated Thyroid Cancer: A 1-Year Follow-Up. Surgical Laparoscopy, Endoscopy \& Percutaneous Techniques, 19, 290-292. http://dx.doi.org/10.1097/SLE.0b013e3181b160da 